\title{
New Type of Donor-Acceptor Through-Space Conjugated Polymer
}

\author{
Lin Lin, Yasuhiro Morisaki, and Yoshiki Chujo \\ Department of Polymer Chemistry, Graduate School of Engineering, Kyoto University, Katsura, Nishikyo-ku, \\ Kyoto 615-8510, Japan
}

Correspondence should be addressed to Yasuhiro Morisaki, ymo@chujo.synchem.kyoto-u.ac.jp and Yoshiki Chujo, chujo@chujo.synchem.kyoto-u.ac.jp

Received 2 November 2009; Accepted 21 February 2010

Academic Editor: Jinying Yuan

Copyright (C) 2010 Lin Lin et al. This is an open access article distributed under the Creative Commons Attribution License, which permits unrestricted use, distribution, and reproduction in any medium, provided the original work is properly cited.

\begin{abstract}
We report the synthesis and properties of a novel through-space conjugated polymer with a [2.2]paracyclophane skeleton. The obtained polymer possessed donor (fluorene) and acceptor (2,1,3-benzothiadiazole) segments that were alternately $\pi$-stacked in proximity via the [2.2] paracyclophane moieties. The good overlap between the emission peak of the donor unit (fluorene) and the CT band of the acceptor unit (2,1,3-benzothiadiazole) caused fluorescence resonance energy transfer, and the visible green light emission from the acceptor unit was observed.
\end{abstract}

\section{Introduction}

Since [2.2] paracyclophane was first prepared by Brown and Farthing in 1949 [1], [2.2] paracyclophane consisting of two benzene rings closely linked (distance of approximately 2.8 $3.1 \AA$ ) by two ethylene bridges at para positions, it has been attracting attention [2-4]. However, even though cyclophane compounds have been receiving considerable attention in the field of organic chemistry, only several reports [5-23] on the synthesis of [2.2] paracyclophane-containing polymers have been published in the field of polymer chemistry. In particular, only a few reports on conjugated polymers containing [2.2] paracyclophane in the polymer main chain have been published [5-7, 20-23]. Recently, we successfully synthesized novel through-space conjugated polymers possessing [2.2] paracyclophanes as a repeating unit into the main chain [5-7, 24-38]. We elucidated their properties and found that the conjugation lengths of these polymers extend via the stacked $\pi$-electron systems. In addition, we synthesized [2.2] paracyclophane-layered polymers by treating pseudop-diethynyl[2.2]paracyclophane with diiodoxanthene as a scaffold [39-42].

A one-dimensional $\pi$-stacked structure can be readily obtained by incorporating a [2.2] paracyclophane unit into a conjugated polymer backbone. As shown in Scheme 1, for example, copolymerization of pseudo- $p$-die- thynyl[2.2] paracyclophane with 2,5-dialkoxy-1,4-diiodobenzene yields a through-space conjugated polymer comprising a stacked $\pi$-electron system, that is, a stacked xylyl-phenylene-xylyl unit. Therefore, the properties of through-space conjugated polymers synthesized by using a [2.2] paracyclophane monomer depend on this stacked $\pi$ electron system (Scheme 1). We elucidated that the polymer emitted efficiently $\left(\Phi_{\mathrm{F}}=82 \%\right.$ in diluted $\mathrm{CHCl}_{3}$ solution) [35] not from the excimer of the stacked xylyl-phenylenexylyl segments but from the xylyl-phenylene-xylyl segment itself, irrespective of the $\pi$-stacked structure of the polymer chain $[6,7,43-45]$.

The use of [2.2] paracyclophane as a monomer for the synthesis of a conjugated polymer enables the development of $\pi$-stacked structures of various $\pi$-electron systems. Such through-space conjugated polymers can be expected to transfer charge and/or energy effectively via the throughspace interaction. Here, we report the synthesis of a new type of donor-acceptor through-space conjugated polymer with fluorene as a donor component and 2,1,3-benzothiadiazole as an acceptor component. The obtained polymer comprises donor and acceptor $\pi$-electron systems that are alternately $\pi$-stacked in proximity and held by covalent bonds, while the construction of $\pi$-stacked donor-acceptor systems has been achieved by a supramolecular approach [46-50]. 

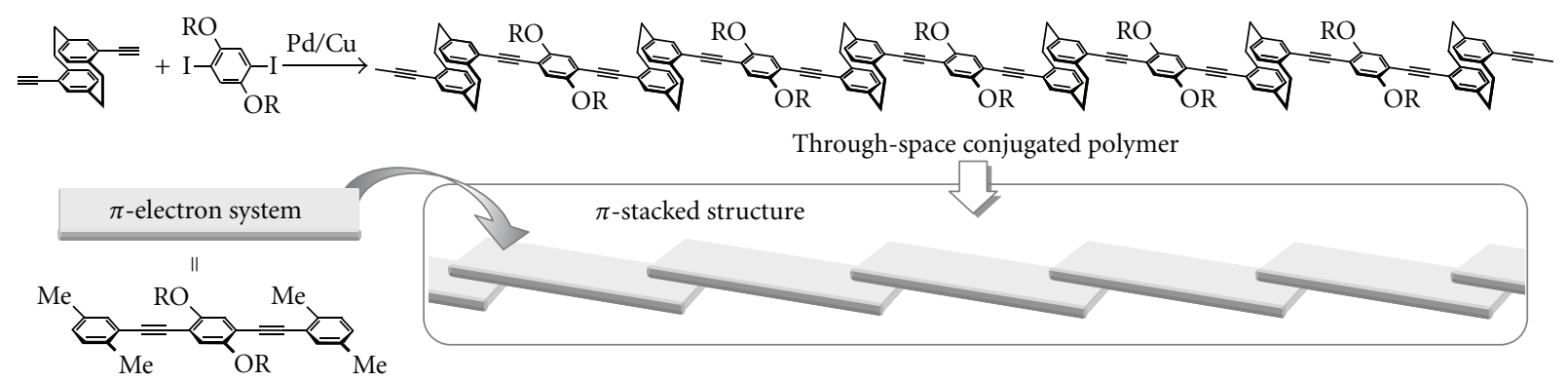

Scheme 1: $\pi$-Stacked structure of a through-space conjugated polymer based on [2.2]paracyclophane.

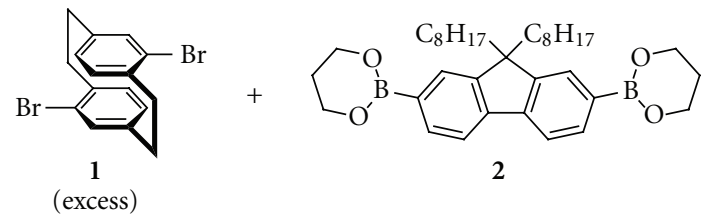

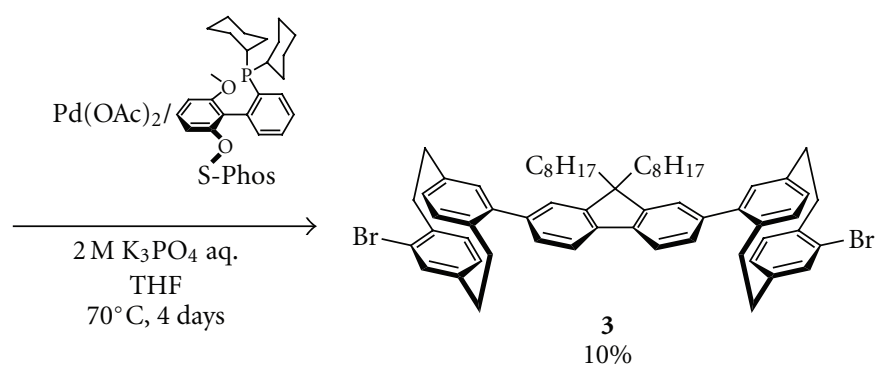

SCHEME 2: Synthesis of monomer 3.

\section{Experimental Section}

2.1. General. ${ }^{1} \mathrm{H}$ and ${ }^{13} \mathrm{C}$ NMR spectra were recorded on a JEOL JNM-EX400 instrument at 400 and $100 \mathrm{MHz}$, respectively. The chemical shift values were expressed relative to $\mathrm{Me}_{4} \mathrm{Si}$ as an internal standard. FTIR spectra were obtained on a Perkin-Elmer 1600 spectrometer. High-resolution mass spectra (HRMS) were obtained on a JEOL JMS-SX102A spectrometer. Analytical thin-layer chromatography (TLC) was performed with silica gel 60 Merck $\mathrm{F}_{254}$ plates. Column chromatography was performed with Wakogel C300 silica gel. Gel permeation chromatography (GPC) was carried out on a TOSOH 8020 (TSKgel $\alpha$-3000 column) instrument using $\mathrm{CHCl}_{3}$ as an eluent after calibration with standard polystyrene samples. Recyclable preparative highperformance liquid chromatography (HPLC) was performed in Japan Analytical Industry Co. Ltd., Model 918R (JAIGEL$2.5 \mathrm{H}$ and $3 \mathrm{H}$ columns) using $\mathrm{CHCl}_{3}$ as an eluent. UV-Vis absorption spectra were obtained on a Shimadzu UV3600 spectrometer. Photoluminescence spectra were obtained on a HORIBA Jobin Yvon FluoroMax-4 luminescence spectrometer. For cyclic voltammetry, a polymer thin film was obtained by spin-coating from a toluene solution on an indiumtin-oxide (ITO) coated-glass electrode. Cyclic voltammetry (CV) was carried out on a BAS CV-50W electrochemical analyzer in $\mathrm{CH}_{3} \mathrm{CN}$ containing $0.1 \mathrm{M} \mathrm{Et}_{4} \mathrm{NBF}_{4}$ with a glassy carbon working electrode, a Pt counter electrode, an $\mathrm{Ag} / \mathrm{Ag}^{+}$ reference electrode, and ferrocene $\left(\mathrm{Fc} / \mathrm{Fc}^{+}\right)$as an external standard at a scan rate of $100 \mathrm{mV} / \mathrm{s}$. Thermogravimetric analysis (TGA) was made on a Seiko EXSTAR 6000 instrument $\left(10^{\circ} \mathrm{C} / \mathrm{min}\right)$. Elemental analyses were performed with an Elementar Analysensysteme varioMICRO V1.5.8 system using the $\mathrm{CHN}$ mode or performed at the Microanalytical Center of Kyoto University.

2.2. Materials. Dehydrated toluene was purchased and used without further purification. THF was purchased and purified by passage through purification column under $\mathrm{Ar}$ pressure [51]. $\mathrm{Pd}\left(\mathrm{PPh}_{3}\right)_{4}, \mathrm{Pd}(\mathrm{OAc})_{2}, 2$-dicyclohexylphosphino-2', $6^{\prime}$-dimethoxybiphenyl (S-Phos), $\mathrm{K}_{2} \mathrm{CO}_{3}$, and $\mathrm{K}_{3} \mathrm{PO}_{4}$ were used as received. 9,9-Dioctylfluorene-2,7diboronic acid bis(1,3-propanediol)ester (2), 1-bromo-2,5dimethylbenzene (5), and 2,5-dimethylphenylboronic acid (6) were purchased and used without further purification. Pseudo- $p$-dibromo[2.2] paracyclophane (1) [52, 53], 4,7bis $(4,4,5,5$-tetramethyl-1,3,2-dioxaborolan-2-yl)-2,1,3-benzothiadiazole (4) [54], and 4,7-dibromo-2,1,3-benzothiadiazole (7) [55] were prepared according to the literature. All reactions were performed under Ar atmosphere.

2.3. 9,9-Dioctyl-2,7-bis(pseudo-p-bromo[2.2]paracyclophanyl)fluorene (3). A mixture of pseudo-p-dibromo[2.2] paracyclophane (1) (366 mg, $1.0 \mathrm{mmol}$ ), 9,9-dioctylfluorene2,7-diboronic acid bis(1,3-propanediol)ester (2) (150 mg, 

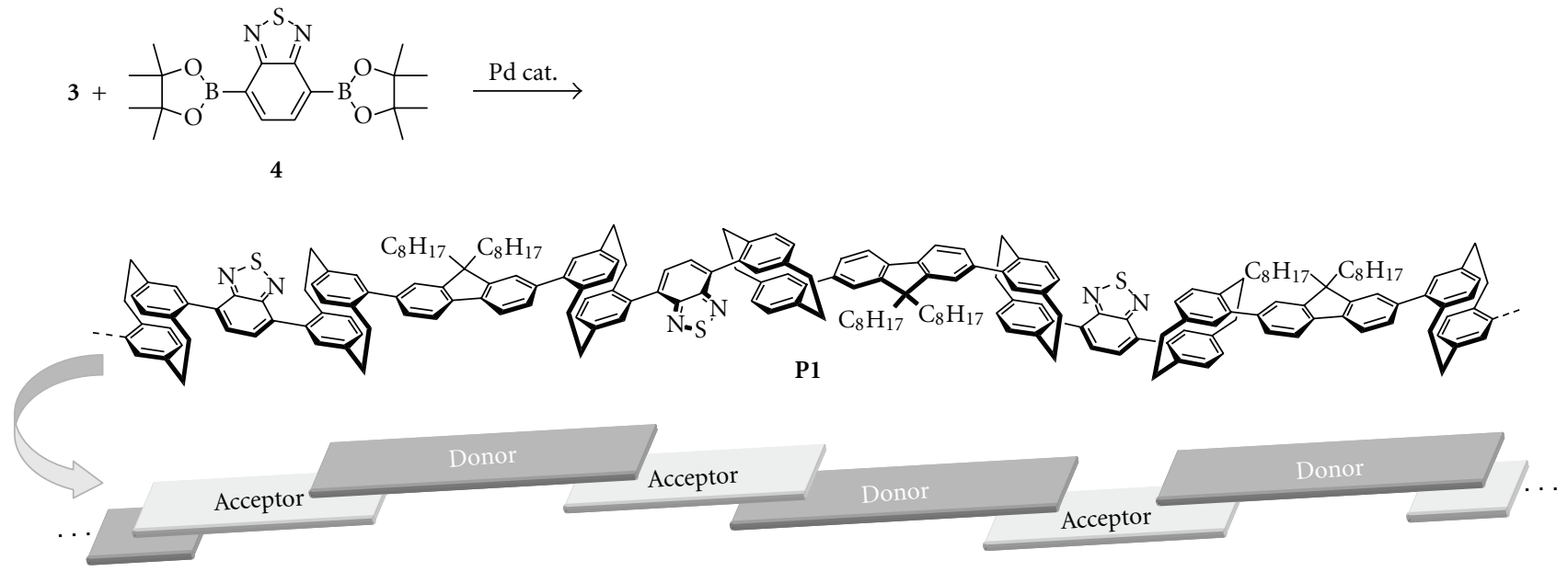

Scheme 3: Synthesis of polymer P1.

TABle 1: Polymerization results.

\begin{tabular}{|c|c|c|c|c|c|c|}
\hline Run & $\begin{array}{c}\text { Catalyst system } \\
\text { Inorganic base, }{ }^{*} \text { solvent }\end{array}$ & Temperature $/{ }^{\circ} \mathrm{C}$ & Time/h & Yield**/\% & $M_{\mathrm{w}}^{* * *}$ & $M_{\mathrm{n}}{ }^{* * *}$ \\
\hline 1 & $\begin{array}{c}\mathrm{Pd}\left(\mathrm{PPh}_{3}\right)_{4} \\
\mathrm{~K}_{2} \mathrm{CO}_{3} \text {, toluene }\end{array}$ & 80 & 96 & 14 & 3700 & 3300 \\
\hline 2 & $\begin{array}{c}\mathrm{Pd}(\mathrm{OAc})_{2} / \mathrm{S}-\mathrm{Phos}^{* * * *} \\
\mathrm{~K}_{3} \mathrm{PO}_{4}, \mathrm{THF}\end{array}$ & $\operatorname{reflux}^{* * * * *}$ & 24 & 68 & 49000 & 17000 \\
\hline
\end{tabular}

$0.30 \mathrm{mmol}), \mathrm{Pd}(\mathrm{OAc})_{2}(6.7 \mathrm{mg}, 0.030 \mathrm{mmol})$, and S-Phos (24 mg, $0.060 \mathrm{mmol}$ ) was placed in a Schlenk tube equipped with a magnetic stirring bar. THF $(9.0 \mathrm{~mL})$ and aqueous $2.0 \mathrm{M} \mathrm{K}_{3} \mathrm{PO}_{4}(0.45 \mathrm{~mL})$ were added, and the reaction was carried out for 4 days at $70^{\circ} \mathrm{C}$. After the reaction, the reaction mixture was poured into $\mathrm{H}_{2} \mathrm{O}$, and extraction with $\mathrm{CHCl}_{3}$ was carried out. The organic layer was dried over $\mathrm{MgSO}_{4}$. After $\mathrm{MgSO}_{4}$ was filtered off, solvent was removed in vacuo. The crude solid was purified by column chromatography on silica gel (eluent: $\mathrm{CHCl}_{3} /$ hexane, v/v $=1 / 3$ ). Further purification by HPLC yielded monomer 3 as a white solid (30 mg, $0.030 \mathrm{mmol}, 10 \%$ ).

$R_{\mathrm{f}}=0.40$ (hexane $\left./ \mathrm{CHCl}_{3}, \mathrm{v} / \mathrm{v}=1 / 3\right) ;{ }^{1} \mathrm{H} \mathrm{NMR}\left(\mathrm{CD}_{2} \mathrm{Cl}_{2}\right.$, $400 \mathrm{MHz}) \delta 0.61(\mathrm{t}, J=6.8 \mathrm{~Hz}, 3 \mathrm{H}), 0.7(\mathrm{br}, 8 \mathrm{H}), 0.73(\mathrm{t}, J=$ $6.8 \mathrm{~Hz}, 6 \mathrm{H}), 0.79, J=7.0 \mathrm{~Hz}, 3 \mathrm{H}), 1.0-1.3(\mathrm{~m}, 40 \mathrm{H}), 2.0(\mathrm{~m}$, $4 \mathrm{H}), 2.1(\mathrm{~m}, 4 \mathrm{H}), 2.54(\mathrm{~m}, 4 \mathrm{H}), 2.68(\mathrm{~m}, 4 \mathrm{H}), 2.90(\mathrm{~m}, 8 \mathrm{H})$, $3.01(\mathrm{~m}, 4 \mathrm{H}), 3.19(\mathrm{~m}, 4 \mathrm{H}), 3.45(\mathrm{~m}, 8 \mathrm{H}), 6.54(\mathrm{~m}, 16 \mathrm{H})$, $6.61(\mathrm{~s}, 4 \mathrm{H}), 7.08(\mathrm{~d}, J=7.8 \mathrm{~Hz}, 4 \mathrm{H}), 7.36(\mathrm{~s}, 4 \mathrm{H}), 7.44(\mathrm{~d}$, $J=8.0 \mathrm{~Hz}, 4 \mathrm{H}), 7.80(\mathrm{~d}, J=7.8 \mathrm{~Hz}, 4 \mathrm{H}) \mathrm{ppm} ;{ }^{13} \mathrm{C} \mathrm{NMR}$ $\left(\mathrm{CD}_{2} \mathrm{Cl}_{2}, 100 \mathrm{MHz}\right) \delta 14.2,22.9,24.5,29.6,29.8,30.4,30.5$, $32.0,32.1,32.3$, 33.6, 34.4, 34.5, 35.8, 41.0, 55.6, 120.2, 125.1, $126.8,128.6,128.8,129.3,132.4,134.2,135.5,137.3,137.6$, $139.3,139.9,140.2,140.4,142.3,143.0,147.2,151.6 \mathrm{ppm}$. HRMS (EI): calcd. for $\mathrm{C}_{61} \mathrm{H}_{68} \mathrm{Br}_{2}[\mathrm{M}]^{+}$: 958.3688, found 958.3668. Anal. calcd. for $\mathrm{C}_{61} \mathrm{H}_{68} \mathrm{Br}_{2}$ : C 76.24; $\mathrm{H}$ 7.13; $\mathrm{Br}$ 16.63, found: C 76.08; H 7.12; Br 16.82.
2.4. Polymerization. A typical procedure is as follows. A mixture of 3 (30 mg, $0.030 \mathrm{mmol}$ ), 4,7-bis(4,4,5,5-tetramethyl1,3,2-dioxaborolan-2-yl)-2,1,3-benzothiadiazole (4) (12 mg, $0.030 \mathrm{mmol}), \mathrm{Pd}(\mathrm{OAc})_{2}(1.4 \mathrm{mg}, 0.006 \mathrm{mmol})$, and S-Phos $(5.0 \mathrm{mg}, 0.012 \mathrm{mmol}$ ) was placed in a Schlenk tube equipped with a magnetic stirring bar. THF $(3.0 \mathrm{~mL})$ and aqueous $2.0 \mathrm{M} \mathrm{K}_{3} \mathrm{PO}_{4}(0.10 \mathrm{~mL})$ were added, and the reaction was carried out for 24 hours at reflux temperature (bath temp.: $75^{\circ} \mathrm{C}$ ). After the reaction mixture was cooled to room temperature, the mixture was filtered to remove precipitated salts and washed with $\mathrm{CHCl}_{3}$. The filtrate was washed with $28 \%$ aqueous $\mathrm{NH}_{3}$ solution, and the organic layer was poured into a large amount of $\mathrm{MeOH}$ to obtain polymer P1 (19 $\mathrm{mg}, 0.080 \mathrm{mmol}, 68 \%$ ) as a yellow powder.

${ }^{1} \mathrm{H}$ NMR $\left(\mathrm{CD}_{2} \mathrm{Cl}_{2}, 400 \mathrm{MHz}\right) \delta 0.8-1.0$ (br m), 1.0-1.4 (br m), 1.7 (br), 2.2 (br), 2.8-3.2 (br m), 3.7 (br), 6.77.1 (m), 7.6-7.7 (br), 8.0 (m) ppm; ${ }^{13} \mathrm{C} \mathrm{NMR}\left(\mathrm{CD}_{2} \mathrm{Cl}_{2}\right.$, $100 \mathrm{MHz}) \delta 13.5,22.2,23.8,29(\mathrm{~m}), 31(\mathrm{~m}), 34(\mathrm{~m}), 40.3$, 55.0, 119.6, 124.3, 129.4, 131-134 (m), 139 (m), 142.1, 151.0, $153.8 \mathrm{ppm}$.

2.5. 9,9-Dioctyl-2,7-dixylylfluorene (M1). A mixture of 2 (420 mg, $0.75 \mathrm{mmol}$ ), 1-bromo-2,5-dimethylbenzene (5) (276 mg, $1.5 \mathrm{mmol}), \mathrm{Pd}(\mathrm{OAc})_{2}(1.12 \mathrm{mg}, 0.005 \mathrm{mmol})$, and S-Phos $(4.1 \mathrm{mg}, 0.010 \mathrm{mmol})$ were placed in a Schlenk tube equipped with a magnetic stirring bar. THF $(1.0 \mathrm{~mL})$ and 


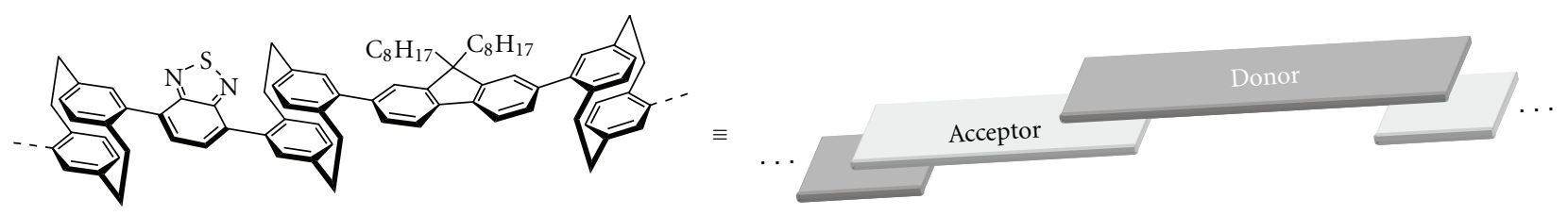

P1

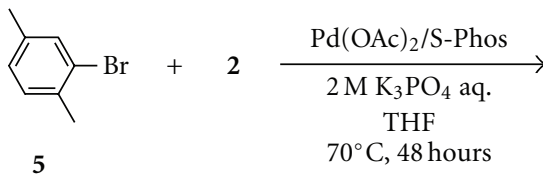

5

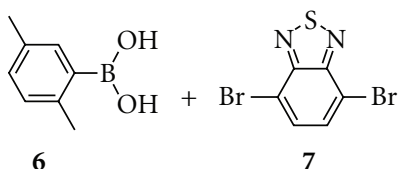

6
7

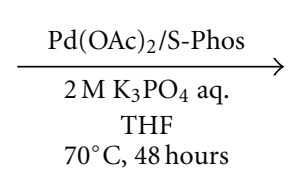

$70^{\circ} \mathrm{C}, 48$ hours

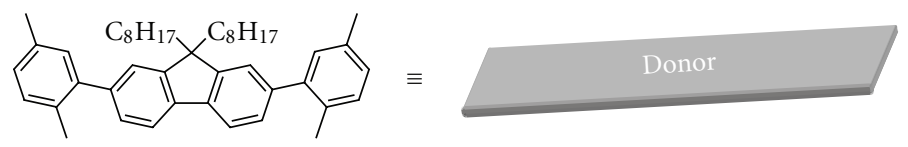

M1

Scheme 4: Synthesis of model compounds M1 and M2.

aqueous $2.0 \mathrm{M} \mathrm{K}_{3} \mathrm{PO}_{4}(0.10 \mathrm{~mL})$ was added, and the reaction was carried out for 48 hours at $70^{\circ} \mathrm{C}$. After the reaction mixture was cooled to room temperature, the mixture was filtered to remove precipitated salts and washed with $\mathrm{CHCl}_{3}$. The organic layer was dried over $\mathrm{MgSO}_{4} \cdot \mathrm{MgSO}_{4}$ was removed, and the solvent was dried in vacuo. The solid was purified by column chromatography on silica gel (eluent: $\mathrm{CHCl}_{3} /$ hexane, $\mathrm{v} / \mathrm{v}=3 / 1$ ) to yield model compound $\mathrm{M} 1$ as a white solid (217 mg, $0.36 \mathrm{mmol}, 48 \%$ ).

$R_{\mathrm{f}}=0.85\left(\mathrm{CHCl}_{3} /\right.$ hexane, $\left.\mathrm{v} / \mathrm{v}=3 / 1\right) ;{ }^{1} \mathrm{H} \mathrm{NMR}\left(\mathrm{CDCl}_{3}\right.$, $400 \mathrm{MHz}) \delta 0.74(\mathrm{br}, 4 \mathrm{H}), 0.81(\mathrm{t}, J=7.1 \mathrm{~Hz}, 6 \mathrm{H}), 1.06(\mathrm{~m}$, $16 \mathrm{H}), 1.19(\mathrm{t}, J=6.8 \mathrm{~Hz}, 4 \mathrm{H}), 1.98(\mathrm{~m}, 4 \mathrm{H}), 2.27(\mathrm{~s}, 6 \mathrm{H})$, $2.38(\mathrm{~s}, 6 \mathrm{H}), 7.09(\mathrm{~d}, J=7.6 \mathrm{~Hz}, 2 \mathrm{H}), 7.15(\mathrm{~s}, 2 \mathrm{H}), 7.18(\mathrm{~d}$, $J=7.8 \mathrm{~Hz}, 2 \mathrm{H}), 7.28(\mathrm{~d}, J=7.8 \mathrm{~Hz}, 2 \mathrm{H}), 7.29(\mathrm{~s}, 2 \mathrm{H}), 7.74$ $(\mathrm{d}, J=7.6 \mathrm{~Hz}, 2 \mathrm{H}) \mathrm{ppm} ;{ }^{13} \mathrm{C} \mathrm{NMR}\left(\mathrm{CDCl}_{3}, 100 \mathrm{MHz}\right) \delta$ $14.1,20.1,20.9,22.6,23.8,29.1,29.2,30.0,31.8,40.4,55.1$, $119.2,123.8,127.79,127.84,130.3,130.5,132.3,135.1,139.5$, 140.7, 142.3, 150.6 ppm. HRMS (EI): calcd. for $\mathrm{C}_{45} \mathrm{H}_{58}[\mathrm{M}]^{+}$: 598.4539, found 598.4541. Anal. calcd. for $\mathrm{C}_{45} \mathrm{H}_{58}$ : C 90.24; H 9.76, found: C 90.18; H 9.73.

2.6. 4,7-Dixylyl-2,1,3-benzothiadiazole (M2). A mixture of 2, 5-dimethylphenylboronic acid (6) (375 mg, $2.5 \mathrm{mmol})$, 4,7dibromo-2,1,3-benzothiadiazole (7) (293 mg, $1.0 \mathrm{mmol}$ ), $\mathrm{Pd}(\mathrm{OAc})_{2}(8.98 \mathrm{mg}, 0.040 \mathrm{mmol})$, and S-Phos $(32.8 \mathrm{mg}$, $0.080 \mathrm{mmol}$ ) were placed in a Schlenk tube equipped with a magnetic stirring bar. THF $(2.0 \mathrm{~mL})$ and aqueous $2.0 \mathrm{M}$ $\mathrm{K}_{3} \mathrm{PO}_{4}(0.20 \mathrm{~mL})$ was added, and the reaction was carried out for 48 hours at $70^{\circ} \mathrm{C}$. After the reaction mixture was cooled to room temperature, the mixture was filtered to remove precipitated salts and washed with $\mathrm{CHCl}_{3}$. The organic layer was dried over $\mathrm{MgSO}_{4} \cdot \mathrm{MgSO}_{4}$ was removed, and the solvent was dried in vacuo. The solid was purified by column chromatography on silica gel (eluent: $\mathrm{CHCl}_{3} /$ hexane, v/v = $1 / 1$ ) to yield model compound M2 as a white solid (240 mg, $0.70 \mathrm{mmol}, 70 \%)$.

$R_{\mathrm{f}}=0.43$ (hexane/ $\left.\mathrm{CHCl}_{3}, \mathrm{v} / \mathrm{v}=1 / 1\right) ;{ }^{1} \mathrm{H} \mathrm{NMR}\left(\mathrm{CD}_{2} \mathrm{Cl}_{2}\right.$, $400 \mathrm{MHz}) \delta 2.14(\mathrm{~s}, 6 \mathrm{H}), 2.39(\mathrm{~s}, 6 \mathrm{H}), 7.21(\mathrm{~s}, 4 \mathrm{H})$, $7.26(\mathrm{~d}, J=8.3 \mathrm{~Hz}, 2 \mathrm{H}), 7.54(\mathrm{~s}, 2 \mathrm{H}), \mathrm{ppm} ;{ }^{13} \mathrm{C} \mathrm{NMR}$ $\left(\mathrm{CDCl}_{3}, 100 \mathrm{MHz}\right) \delta 19.2,20.2,128.5,128.7,129.7,130.4$, 133.1, 134.0, 134.8, 137.1, 153.7 ppm. HRMS (EI): calcd. for $\mathrm{C}_{22} \mathrm{H}_{20} \mathrm{~N}_{2} \mathrm{~S}[\mathrm{M}]^{+}: 344.1347$, found 344.1344. Anal. calcd. for $\mathrm{C}_{22} \mathrm{H}_{20} \mathrm{~N}_{2} \mathrm{~S}$ : C 76.71; H 5.85; N 8.13; S 9.31, found: C 76.52; H 5.86; N 7.82; S 9.07.

${ }^{1} \mathrm{H}$ and ${ }^{13} \mathrm{C}$ NMR spectra of all compounds described above are shown in Supplementary Material available online doi:10.115/2010/908128 Information.

\section{Results and Discussion}

The synthesis of monomer 3 is outlined in Scheme 2 . The treatment of the excess amount ( $>2.5$ equivalent) of pseudo-p-dibromo[2.2] paracyclophane 1 with fluorene diboronic acid ester 2 in the presence of a catalytic amount of $\mathrm{Pd}(\mathrm{OAc})_{2}$ and 2-dicyclohexylphosphino$2^{\prime}, 6^{\prime}$-dimethoxybiphenyl (S-Phos) in THF with aqueous $\mathrm{K}_{3} \mathrm{PO}_{4}[56,57]$ afforded the corresponding bis(pseudop-bromo[2.2] paracyclophanyl)fluorene 3 in 10\% isolated yield. The purification of monomer 3 by column chromatography using $\mathrm{SiO}_{2}$ and recyclable HPLC resulted in this low isolated yield (10\%). The ${ }^{1} \mathrm{H}$ NMR spectrum of monomer 3 exhibited two peaks at around $2.1 \mathrm{ppm}$ (approximately 1:1), as shown in Figure S1; these peaks were assigned to the methylenes of octyl groups at the 9-position of fluorene. This result suggests that the existence of two isomers was 
attributed to the two diastereomers (racemi and meso) derived from two planar chiral [2.2] paracyclophane units in monomer 3.

Polymer P1 was synthesized by the palladium-catalyzed polymerization of 3 and 4,7-bis(4,4,5,5-tetramethyl-1,3,2dioxaborolan-2-yl)-2,1,3-benzothiadiazole 4 , as shown in Scheme 3. The palladium-catalyzed coupling reaction of monomers 3 and 4 was carried out to obtain the corresponding through-space conjugated polymer $\mathbf{P 1}$; the polymerization results are listed in Table 1. An appropriate catalytic system was critically important for achieving successful polymerization. The standard Suzuki-Miyaura coupling reaction [56] with a $\mathrm{Pd}\left(\mathrm{PPh}_{3}\right)_{4}$ catalyst and aqueous $\mathrm{K}_{2} \mathrm{CO}_{3}$ in toluene at $80^{\circ} \mathrm{C}$ for 96 hours was ineffective for polymerization. Polymer P1 was obtained in $14 \%$ isolated yield with a number-average molecular weight $\left(M_{\mathrm{n}}\right)$ of 3300 and a weight-average molecular weight $\left(M_{\mathrm{w}}\right)$ of 3700 by $\mathrm{GPC}$ analysis $\left(\mathrm{CHCl}_{3}\right.$, polystyrene standards, Run 1 in Table 1). $\mathrm{Pd}(\mathrm{OAc})_{2}$ with S-Phos catalytic system considerably increased the catalytic activity for the polymer synthesis as well as the monomer synthesis to afford polymer P1 in 68\% isolated yield, and the $M_{\mathrm{n}}$ and $M_{\mathrm{w}}$ were estimated to be 17000 and 49000, respectively (Run 2 in Table 1).

The obtained polymer $\mathbf{P} \mathbf{1}$ is a new type of donor-acceptor conjugated polymer in which a donor $\pi$-electron system and an acceptor $\pi$-electron system are linked alternately via the through-space interaction in the single polymer main chain (Scheme 3). The structure of $\mathbf{P} \mathbf{1}$ was confirmed by ${ }^{1} \mathrm{H}$ and ${ }^{13} \mathrm{C}$ NMR spectra (Figures S3 and S4 in Supplementary Material). Polymer $\mathbf{P} \mathbf{1}$ was highly soluble in common organic solvents such as THF, $\mathrm{CHCl}_{3}, \mathrm{CH}_{2} \mathrm{Cl}_{2}$, toluene, and DMF. In addition, it could be processed into a thin film by casting or spin-coating from toluene solution, and it was found to be air stable in solution and in the solid state. The thermal stability of $\mathbf{P 1}$ was evaluated by carrying out thermogravimetric analysis (TGA) under air (Figure S9 in Supplementary Material). The TGA results showed that P1 exhibited good thermal stability with a $10 \%$ weight loss and temperature at $408^{\circ} \mathrm{C}$.

In order to elucidate the optical properties of polymer P1, we designed and prepared model compounds M1 and M2. These compounds M1 and M2 represent the donor and acceptor unit layers of $\mathbf{P 1}$, respectively, as shown in Scheme 4. Figure 1 shows UV-Vis absorption spectra and photoluminescence spectra of $\mathbf{M 1}, \mathbf{M} 2$, and P1 in diluted $\mathrm{CHCl}_{3}\left(1.0 \times 10^{-5} \mathrm{M}\right.$ for UV and $1.0 \times 10^{-6} \mathrm{M}$ for photoluminescence). As shown in Figure 1(a), the typical $\pi-\pi^{*}$ transition band of a fluorene compound was observed at around $300 \mathrm{~nm}$, and blue emission was observed at $364 \mathrm{~nm}$ with a vibrational structure.

As shown in Figure 1(b), M2 exhibited a broad absorption band at around $360 \mathrm{~nm}$, which was attributed to a charge-transfer (CT) band from the benzene to the thiadiazole moieties, in addition to a $\pi-\pi^{*}$ transition band of xylyl-phenylene-xylyl backbone at around $310 \mathrm{~nm}$. When the CT band at $360 \mathrm{~nm}$ was excited, the photoluminescence spectrum of M2 showed a maximum peak at $467 \mathrm{~nm}$. The shape and the peak top of the photoluminescence spectrum of $\mathbf{M} 2$ were independent of the excitation wavelength $(308 \mathrm{~nm}$ and

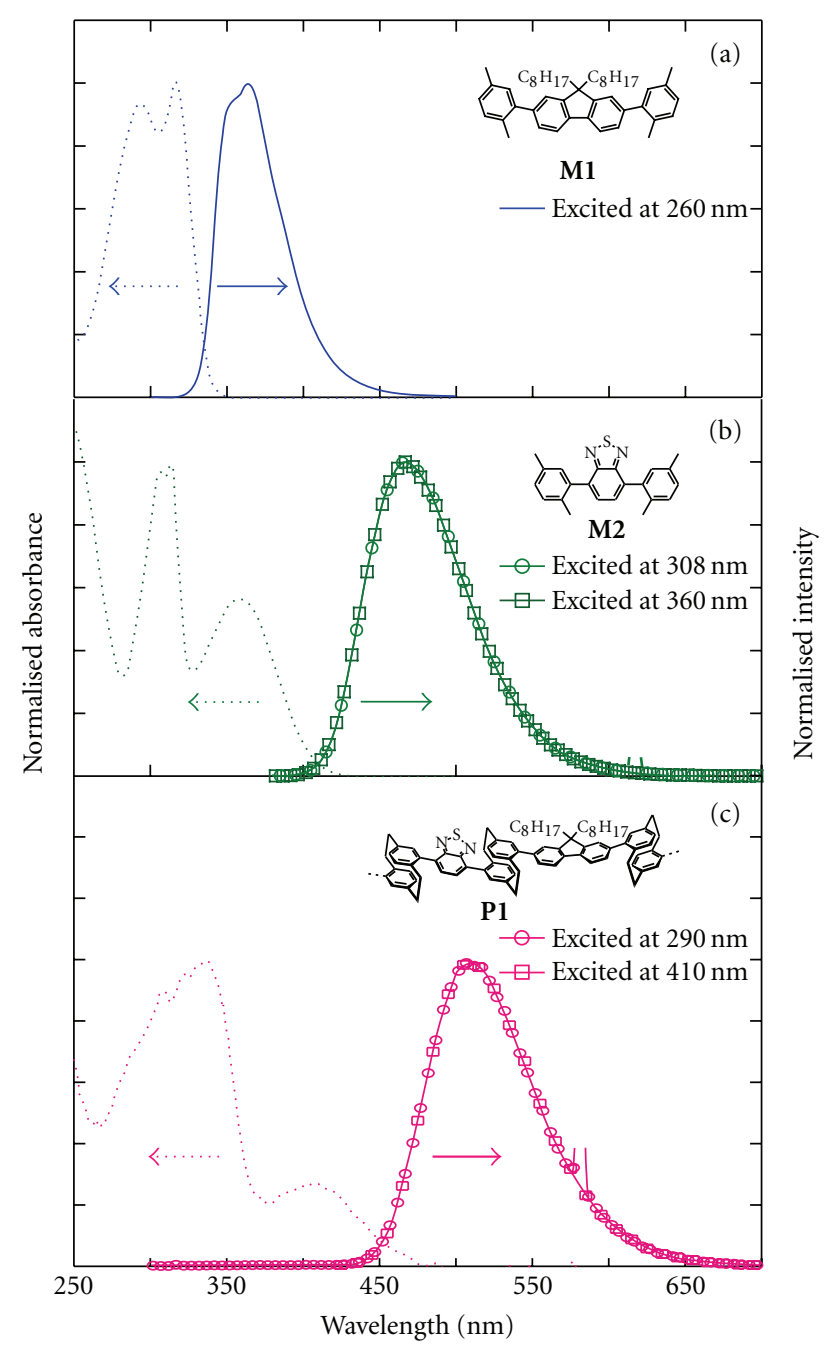

FIGURE 1: UV-Vis absorption spectra and photoluminescence spectra of (a) model compounds M1, (b) M2, and (c) polymer P1 in $\mathrm{CHCl}_{3}\left(1.0 \times 10^{-5} \mathrm{M}\right.$ for UV and $1.0 \times 10^{-6} \mathrm{M}$ for photoluminescence). Scattered light was deleted from the spectra.

$360 \mathrm{~nm}$ ), indicating that the spectrum is characteristic of the benzothiadiazole moiety.

As shown in Figure 1(c), polymer P1 exhibited a UV spectrum with two absorption bands at around $330 \mathrm{~nm}$ and $400 \mathrm{~nm}$. According to the UV-Vis absorption spectra of M1 and M2 (Figures 1(b) and 1(c), resp.), it was observed that the spectrum of $\mathbf{P} 1$ comprises the $\pi-\pi^{*}$ bands of $\mathbf{M} 1$ and $\mathbf{M} 2$ segments and the CT band of the benzothiadiazole moiety. In contrast, the absorption spectrum of $\mathbf{P 1}$ exhibited a red shift of approximately $50 \mathrm{~nm}$ in comparison with the absorption spectra of $\mathbf{M} 1$ and $\mathbf{M} 2$, because of the through-space conjugation. As in the case of $\mathbf{M} 2$, the photoluminescence spectrum of P1 exhibited a broad peak at around $505 \mathrm{~nm}$. The photoluminescence spectra obtained at excitation wavelengths of $290 \mathrm{~nm}$ and $410 \mathrm{~nm}$ were identical, as shown in Figure 1(c). In other words, even if the fluorene segments in P1 were excited, only the benzothiadiazole segments emitted. In addition, from the excitation spectrum of polymer P1, 


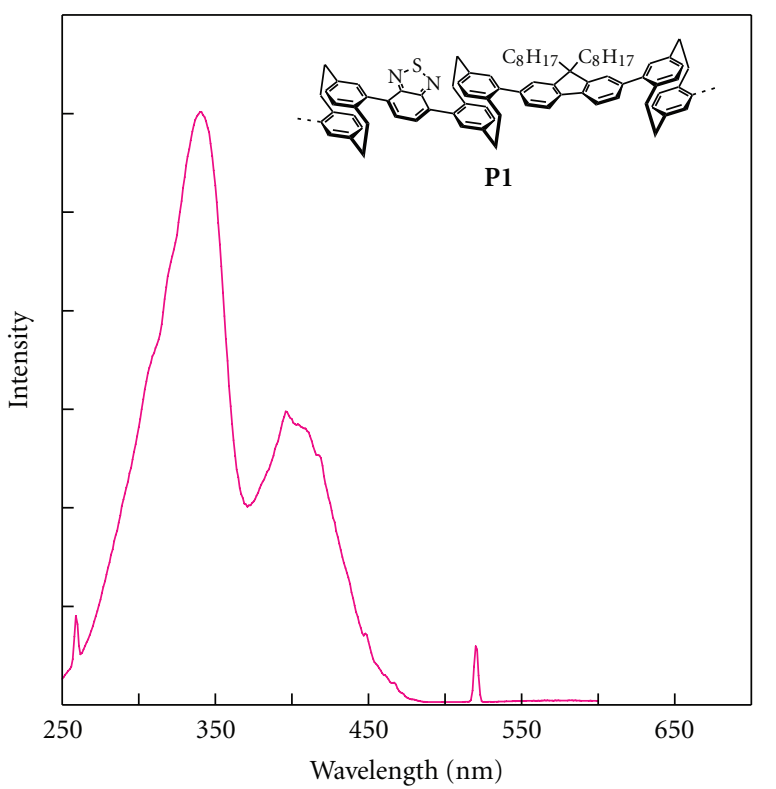

Figure 2: Excitation spectrum of polymer $\mathbf{P 1}$ in $\mathrm{CHCl}_{3}$ (1.0 $\times 10^{-5} \mathrm{M}$ ), monitoring wavelength at $520 \mathrm{~nm}$.

it was confirmed that the benzothiadiazole segments were the emitting species (Figure 2). We confirmed that this concentration $\left(1.0 \times 10^{-6} \mathrm{M}\right)$ was sufficiently diluted to avoid intermolecular interactions according to the concentration effect of the photoluminescence spectra (Figures S11) due to peak shift saturation. These results and the good overlap between the emission peak of M1 and the CT band of M2 suggest the occurrence of fluorescence resonance energy transfer (FRET) [58] from the donor-fluorene segments to the acceptor-benzothiadiazole segments.

Figure 3 shows the photoluminescence spectrum of a mixture of compounds M1 and M2 (concentration of each compound: $1.0 \times 10^{-6} \mathrm{M}$ ) in a diluted $\mathrm{CHCl}_{3}$ solution excited at $300 \mathrm{~nm}$. Emissions from both $\mathbf{M} 1$ and $\mathbf{M} 2$ were observed at $361 \mathrm{~nm}$ and $467 \mathrm{~nm}$, respectively. Increasing the concentration from $1.0 \times 10^{-6} \mathrm{M}$ to $1.0 \times 10^{-4} \mathrm{M}$ resulted in an increase in the intensity of emission from M2 due to the intermolecular interaction. The closely $\pi$-stacked structure of alternate donor-fluorene and acceptor-benzothiadiazole segments in the polymer main chain caused FRET. The absolute photoluminescence quantum efficiency $\left(\Phi_{\mathrm{PL}}\right)$ of $\mathbf{P 1}$ was calculated to be 0.49 , which was lower than that of M2 $\left(\Phi_{\mathrm{PL}}=0.75\right)$. The solvent effect on the photoluminescence of P1 was examined, and the $\Phi_{\mathrm{PL}}$ in more polar solvents such as DMF was 0.42 (Figure S12). This result implies that photoexcited electron transfer as well as energy transfer causes a decrease in the photoluminescence quantum efficiency. Incidentally, the Commission Internationale de L'Eclairage (CIE 1931) coordinates (x,y) of P1 were $(0.2827,0.5192)$ in solution and in the thin film, indicating visible green light emission.

The HOMO and LUMO energy levels of polymer P1 were estimated from the cyclic voltammogram as well as UV-Vis absorption spectrum. The cyclic voltammogram

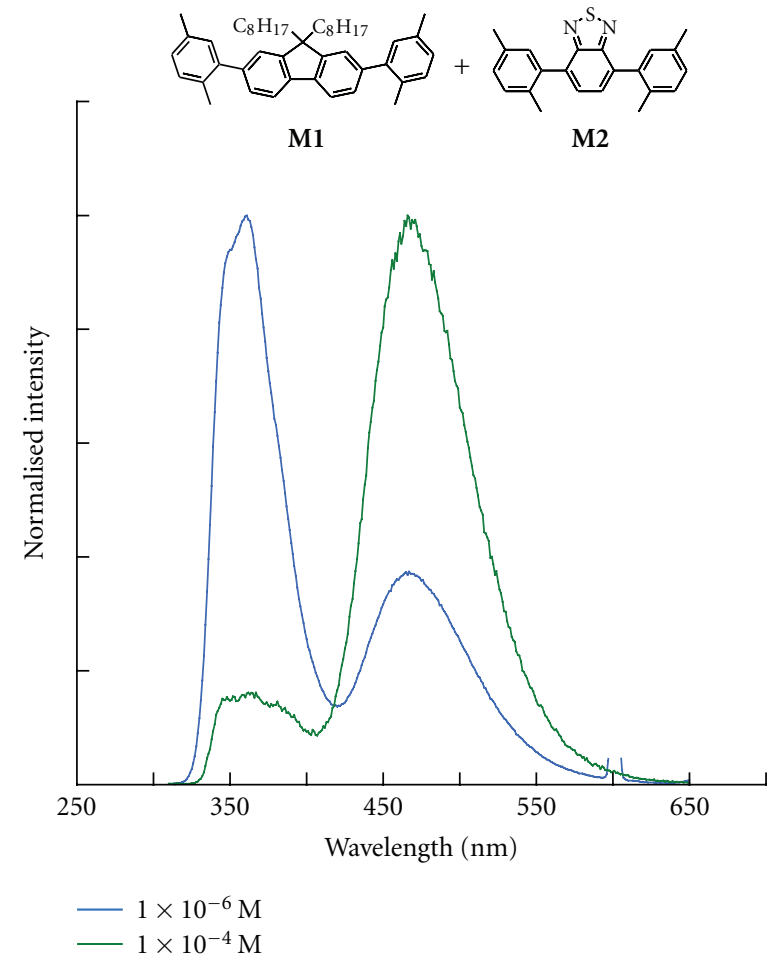

FIgURE 3: Photoluminescence spectrum of the 1:1 mixture of M1 and $\mathbf{M} 2$ in $\mathrm{CHCl}_{3}\left(1.0 \times 10^{-6} \mathrm{M}\right.$ and $\left.1.0 \times 10^{-4} \mathrm{M}\right)$ excited at $300 \mathrm{~nm}$. Scattered light $(600 \mathrm{~nm})$ was deleted from the spectrum.

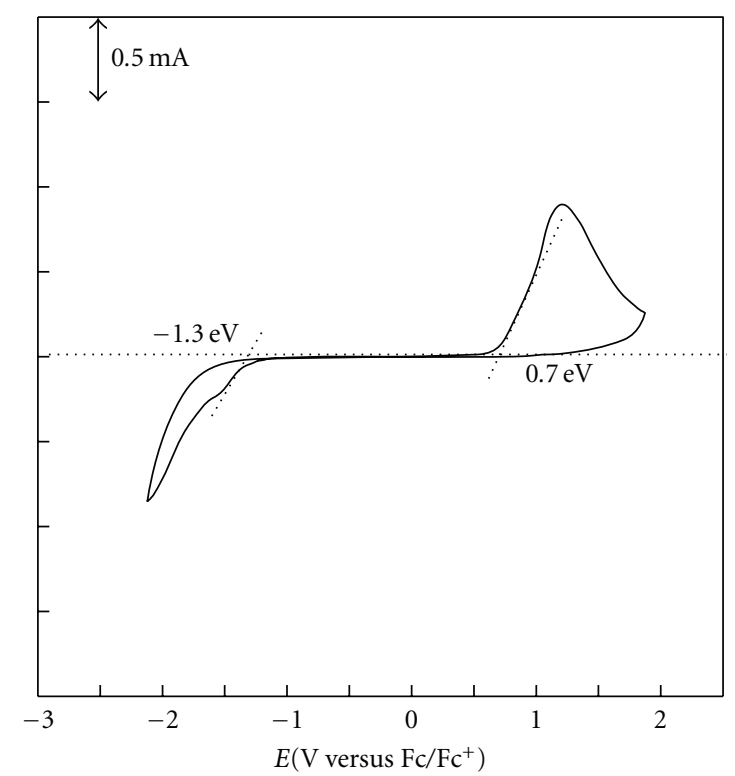

Figure 4: Cyclic voltammogram of polymer P1 on an ITO electrode in $\mathrm{CH}_{3} \mathrm{CN}$ containing $0.1 \mathrm{M} \mathrm{Et}_{4} \mathrm{NBF}_{4}$ (versus $\mathrm{Fc} / \mathrm{Fc}^{+}$) at a scan rate of $100 \mathrm{mV} / \mathrm{s}$.

was obtained by fabricating thin films on an ITO glass electrode in $\mathrm{CH}_{3} \mathrm{CN}$ solution of $0.1 \mathrm{M} \mathrm{Et}_{4} \mathrm{NBF}_{4}$ using a three-electrode cell with a Pt counter electrode, an $\mathrm{Ag} / \mathrm{Ag}^{+}$ reference electrode, and ferrocene $\left(\mathrm{Fc} / \mathrm{Fc}^{+}\right)$as an external 
standard. Figure 4 shows the cyclic voltammogram of P1 at a scan rate of $100 \mathrm{mV} / \mathrm{s}$. The oxidation process of P1 resulted in an onset peak at approximately $0.7 \mathrm{~V}$; in the cathodic scan, the onset reduction potential was observed at approximately $-1.3 \mathrm{~V}$ (versus $\mathrm{Fc} / \mathrm{Fc}^{+}$). The $\mathrm{HOMO}$ and LUMO energy levels of $\mathbf{5}$ were roughly estimated to be $-5.5 \mathrm{eV}$ and $-3.5 \mathrm{eV}$, respectively. The bandgap energy was approximately $2.0 \mathrm{eV}$, which was in agreement with the optical band gap energy (approximately $2.2 \mathrm{eV}$ ) estimated from the absorption spectrum of a thin film made of P1 (onset $\lambda=575 \mathrm{~nm}$, as shown in Figure S10 in Supplementary Material). On the other hand, density functional theory (DFT) calculations at the B3LYP/6-31G* level were carried out for model compounds. As can be seen in Figure S13 in Supplementary Material, the HOMO and LUMO of the polymer comprise the fluorene unit and the benzothiadiazole unit, respectively. Thus, it can be reasonably concluded that both of the electron transfer and the energy transfer from the fluorene unit to the benzothiadiazole unit occurs in the polymer chain (vide supra).

\section{Conclusion}

In summary, we successfully synthesized a novel throughspace conjugated polymer with a [2.2] paracyclophane skeleton. The obtained polymer possessed donor and acceptor segments that were alternately $\pi$-stacked in proximity via the [2.2] paracyclophane moieties. The polymer was soluble in common organic solvents, and a homogeneous thin film was readily obtained by casting or spin-coating techniques. The conjugation length of the polymer was extended by the through-space interaction. The polymer exhibited green emission with $\Phi_{\mathrm{PL}}$ of 0.49 and CIE coordinates of $(0.2827$, 0.5192 ) in a diluted solution. This emission was attributed to the benzothiadiazole moieties; in other words, the benzothiadiazole moieties emitted due to FRET even when the fluorene moieties were excited. The polymer exhibited oxidation and reduction potentials at $0.7 \mathrm{~V}$ and $-1.3 \mathrm{~V}$ (versus $\mathrm{Fc} / \mathrm{Fc}^{+}$), respectively. Finally, it should be emphasized that the polymer is a novel donor-acceptor conjugated polymer that combines the donor and acceptor units alternately through $\pi-\pi$ stacking and not through a bond. Further studies on the synthesis of through-space conjugated polymers containing the donor and acceptor units at each polymer chain end are currently in progress.

\section{Acknowledgments}

This work was supported by Grant-in-Aid for Young Scientists (A) (no. 21685012) from the Ministry of Education, Culture, Sports, Science and Technology, Japan. Financial support from the Mazda Foundation is also acknowledged.

\section{References}

[1] C. J. Brown and A. C. Farthing, "Preparation and structure of di-p-xylylene," Nature, vol. 164, no. 4178, pp. 915-916, 1949.

[2] R. Cleiter and H. Hopf, Eds., Modern Cyclophane Chemistry, Wiley-VCH, Weinheim, Germany, 2004.
[3] H. Hopf, "[2.2]Paracyclophanes in polymer chemistry and materials science," Angewandte Chemie International Edition, vol. 47, no. 51, pp. 9808-9812, 2008.

[4] F. Vögtle, Cyclophane Chemistry, John Wiley \& Sons, New York, NY, USA, 1993.

[5] Y. Morisaki and Y. Chujo, "Through-space conjugated polymers based on cyclophanes," Angewandte Chemie International Edition, vol. 45, no. 39, pp. 6430-6437, 2006.

[6] Y. Morisaki and Y. Chujo, "Cyclophane-containing polymers," Progress in Polymer Science, vol. 33, no. 3, pp. 346-364, 2008.

[7] Y. Morisaki and Y. Chujo, "Synthesis of $\pi$-stacked polymers on the basis of [2.2] paracyclophane," Bulletin of the Chemical Society of Japan, vol. 82, no. 9, pp. 1070-1082, 2009.

[8] S. Iwatsuki, T. Itoh, M. Kubo, and H. Okuno, "Synthesis and polymerization of 4-vinyl [2.2] paracyclophane," Polymer Bulletin, vol. 32, no. 1, pp. 27-34, 1994.

[9] J. Nishimura and S. Yamashita, "C3 cyclopolymerization: cationic cyclopolymerization of 1,3-bis( $p$-vinylphenyl)propane and its derivatives," in Cyclopolymerization and Polymers with Chain-Ring Structures, G. B. Butler and J. E. Kresta, Eds., pp. 177-195, American Chemical Society, Washington, DC, USA, 1982.

[10] J. Furukawa and J. Nishimura, "Cyclopolymerization of $\alpha, \omega$ bis(4-vinylphenyl)alkane-polymer containing [3.3] paracyclophane unit in main chain," Journal of Polymer Science, Part $B$, vol. 14, no. 2, pp. 85-90, 1976.

[11] J. Furukawa and J. Nishimura, "Cationic cyclopolymerization of $\alpha, \omega$-bis(4-vinylphenyl)alkanes-polymer containing [3.3] paracyclophane units in main chain," Journal of Polymer Science Polymer Symposium, no. 56, pp. 437-446, 1976.

[12] J. Nishimura and S. Yamashita, "Polymerization of $\alpha, \omega$ bis(para-isopropenylphenyl)alkanes by means of stannic chloride," Polymer Journal, vol. 11, no. 8, pp. 619-627, 1979.

[13] J. Nishimure, M. Mimura, N. Nakazawa, and S. Yamashita, "C3 cyclopolymerization. II. Charge-transfer cyclopolymerization of 1,3-bis( $p$-vinylphenyl)propane," Journal of Polymer Science, Part A, vol. 18, no. 7, pp. 2071-2084, 1980.

[14] J. Nishimura, M. Furukawa, S. Yamashita, T. Inazu, and T. Yoshino, "C3 cyclopolymerization. IV. Cationic polymerization of 1,3-bis(4-vinylnaphthyl)propane and the polymer structure yielded," Journal of Polymer Science, Part A, vol. 19, no. 12, pp. 3257-3268, 1981.

[15] D. T. Glatzhofer and D. T. Longone, "Extended cooperative electronic effects in poly $((E, E)$-[6.2] paracyclophane-1,5diene)," Journal of Polymer Science, Part A, vol. 24, no. 5, pp. 947-954, 1986.

[16] D. T. Longone and D. T. Glatzhofer, "Cyclopolymerization of (E,E)-[6.2] paracyclophane-1,5-diene," Journal of Polymer Science, Part A, vol. 24, no. 8, pp. 1725-1733, 1986.

[17] J. Ulański, J. Sielski, D. T. Galtzhofer, and M. Kryszewski, "Poly(paracyclophane)—high-mobility photoconducting polymer," Journal of Physics D, vol. 23, no. 1, pp. 75-78, 1990.

[18] J. Ulański, J. Kubacki, I. Glowacki, M. Kryszewski, and D. T. Glatzhofer, "Photoconductivity of poly((E,E)-[6.2] paracyclophane-1,5-diene) and its complex with TCNE," Journal of Applied Polymer Science, vol. 44, no. 12, pp. 2103-2106, 1992.

[19] D. J. Guerrero and D. T. Glatzhofer, "Synthesis and electronic properties of poly $((E, E)-[6.2]-(2,5)$ thiophenophane1,5-diene)," Journal of Polymer Science, Part A, vol. 32, no. 3, pp. 457-464, 1994.

[20] L. Guyard and P. Audebert, "Synthesis and electrochemical polymerization of bis-dithienyl cyclophane," Electrochemistry Communications, vol. 3, no. 4, pp. 164-167, 2001. 
[21] L. Guyard, P. Audebert, W. R. Dolbier Jr., and J.-X. Duan, "Synthesis and electrochemical polymerization of new oligothiophene functionalized fluorocyclophanes," Journal of Electroanalytical Chemistry, vol. 537, no. 1-2, pp. 189-193, 2002.

[22] F. Salhi, B. Lee, C. Metz, L. A. Bottomley, and D. M. Collard, "Influence of $\pi$-stacking on the redox properties of oligothiophenes: ( $\alpha$-alkyloligo-thienyl)para[2.2]cyclophanes," Organic Letters, vol. 4, no. 19, pp. 3195-3198, 2002.

[23] F. Salhi and D. M. Collard, " $\pi$-stacked conjugated polymers: the influence of paracyclophane $\pi$-stacks on the redox and optical properties of a new class of broken conjugated polythiophenes," Advanced Materials, vol. 15, no. 1, pp. 81-85, 2003.

[24] Y. Morisaki and Y. Chujo, "Synthesis of novel $\pi$-conjugated polymers having [2.2] paracyclophane skeleton in the main chain. Extension of $\pi$-conjugated length via the throughspace," Macromolecules, vol. 35, no. 3, pp. 587-589, 2002.

[25] Y. Morisaki and Y. Chujo, "Synthesis of novel alternating $\pi$-conjugated copolymers having [2.2]paracyclophane and fluorene units in the main chain leading to the blue lightemitting materials," Chemistry Letters, no. 2, pp. 194-195, 2002.

[26] Y. Morisaki, T. Ishida, and Y. Chujo, "Synthesis and properties of novel through-space $\pi$-conjugated polymers based on poly ( $p$-phenylenevinylene)s having a [2.2] paracyclophane skeleton in the main chain," Macromolecules, vol. 35, no. 21, pp. 7872-7877, 2002.

[27] Y. Morisaki and Y. Chujo, "Synthesis and optical properties of the [2.2] paracyclophane-containing $\pi$-conjugated polymer with a diacetylene unit," Polymer Bulletin, vol. 49, no. 4, pp. 209-215, 2002.

[28] Y. Morisaki, F. Fujimura, and Y. Chujo, "Synthesis and properties of novel $\sigma$ - $\pi$-conjugated polymers with alternating organosilicon and [2.2]paracyclophane units in the main chain," Organometallics, vol. 22, no. 17, pp. 3553-3557, 2003.

[29] Y. Morisaki and Y. Chujo, "Synthesis and properties of a novel through-space conjugated polymer with [2.2] paracyclophane and ferrocene in the main chain," Macromolecules, vol. 36, no. 25, pp. 9319-9324, 2003.

[30] Y. Morisaki and Y. Chujo, "Novel [2.2]paracyclophanefluorene-based conjugated copolymers: synthesis, optical, and electrochemical properties," Macromolecules, vol. 37, no. 11, pp. 4099-4103, 2004.

[31] Y. Morisaki, T. Ishida, H. Tanaka, and Y. Chujo, "Synthesis and properties of the [2.2] paracyclophane-containing conjugated polymer with benzothiadiazole as an electron acceptor," Journal of Polymer Science, Part A, vol. 42, no. 23, pp. 58915899, 2004.

[32] Y. Morisaki, N. Wada, and Y. Chujo, "Novel conjugated polymers containing [2.2] paracyclophane and carbazole units with efficient photoluminescence," Polymer Bulletin, vol. 53, no. 2, pp. 73-80, 2005.

[33] Y. Morisaki, N. Wada, and Y. Chujo, "Novel $\pi$-conjugated cyclophane polymers containing phenylamine moieties with strong blue-light emission," Polymer, vol. 46, no. 16, pp. 5884$5889,2005$.

[34] Y. Morisaki and Y. Chujo, "Novel through-space conjugated polymers consisting of alternate [2.2]paracyclophane and fluorene," Bulletin of the Chemical Society of Japan, vol. 78, no. 2, pp. 288-293, 2005.

[35] Y. Morisaki, N. Wada, M. Arita, and Y. Chujo, "Synthesis of through-space conjugated polymers containing the pseudoortho-linked [2.2] paracyclophane moiety," Polymer Bulletin, vol. 62, no. 3, pp. 305-314, 2009.
[36] Y. Morisaki, L. Lin, and Y. Chujo, "Through-space conjugated polymer containing [2.2] paracyclophane and dithiafulvene units in the main chain," Polymer Bulletin, vol. 62, no. 6, pp. 737-747, 2009.

[37] Y. Morisaki, L. Lin, and Y. Chujo, "Synthesis of cyanosubstituted through-space poly( $p$-arylenevinylene)," Chemistry Letters, vol. 38, no. 7, pp. 734-735, 2009.

[38] Y. Morisaki, L. Lin, and Y. Chujo, "Synthesis and properties of through-space conjugated polymers based on cyanosubstituted poly( $p$-arylenevinylene)s," Journal of Polymer Science, Part A, vol. 47, no. 22, pp. 5979-5988, 2009.

[39] Y. Morisaki and Y. Chujo, "Construction of benzene ringlayered polymers," Tetrahedron Letters, vol. 46, no. 15, pp. 2533-2537, 2005.

[40] Y. Morisaki, T. Murakami, and Y. Chujo, "Synthesis and properties of [2.2] paracyclophane-layered polymers," Macromolecules, vol. 41, no. 16, pp. 5960-5963, 2008.

[41] Y. Morisaki, T. Murakami, and Y. Chujo, "Synthesis, structure, and properties of aromatic ring-layered polymers containing ferrocene as a terminal unit," Journal of Inorganic and Organometallic Polymers and Materials, vol. 19, no. 1, pp. 104112, 2009.

[42] Y. Morisaki, T. Murakami, T. Sawamura, and Y. Chujo, "[2.2]Paracyclophane-layered polymers end-capped with fluorescence quenchers," Macromolecules, vol. 42, no. 10, pp. 3656-3660, 2009.

[43] W. J. Oldham Jr., Y.-J. Miao, R. J. Lachicotte, and G. C. Bazan, "Stilbenoid dimers: effect of conjugation length and relative chromophore orientation," Journal of the American Chemical Society, vol. 120, no. 2, pp. 419-420, 1998.

[44] G. C. Bazan, W. J. Oldham Jr., R. J. Lachicotte, S. Tretiak, V. Chernyak, and S. Mukamel, "Stilbenoid dimers: dissection of a paracyclophane chromophore," Journal of the American Chemical Society, vol. 120, no. 36, pp. 9188-9204, 1998.

[45] S. Wang, G. C. Bazan, S. Tretiak, and S. Mukamel, "Oligophenylenevinylene phane dimers: probing the effect of contact site on the optical properties of bichromophoric pairs," Journal of the American Chemical Society, vol. 122, no. 7, pp. 1289-1297, 2000.

[46] I. Yamaguchi and T. Yamamoto, "Self-assembly of donor and acceptor $\pi$-conjugated molecules via complexation with $\gamma$ cyclodextrin to give a pseudorotaxane type macromolecular adduct with an expanded $\pi$-conjugation system," Chemistry Letters, no. 9, pp. 938-939, 2002.

[47] R. S. Lokey and B. L. Iverson, "Synthetic molecules that fold into a pleated secondary structure in solution," Nature, vol. 375, no. 25, pp. 303-305, 1995.

[48] X. Zhao, M.-X. Jia, X.-K. Jiang, L.-Z. Wu, Z.-T. Li, and G.-J. Chen, "Zipper-featured $\delta$-peptide foldamers driven by donoracceptor interaction. Design, synthesis, and characterization," Journal of Organic Chemistry, vol. 69, no. 2, pp. 270-279, 2004.

[49] S. Ghosh and S. Ramakrishnan, "Structural fine-tuning of (-donor-spacer-acceptor-spacer-) ${ }_{n}$ type foldamers. Effect of spacer segment length, temperature, and metal-ion complexation on the folding process," Macromolecules, vol. 38, no. 3, pp. 676-686, 2005.

[50] W. Zhang, W. R. Dichtel, A. Z. Stieg, et al., "Folding of a donor-acceptor polyrotaxane by using noncovalent bonding interactions," Proceedings of the National Academy of Sciences of the United States of America, vol. 105, no. 18, pp. 6514-6519, 2008.

[51] A. B. Pangborn, M. A. Giardello, R. H. Grubbs, R. K. Rosen, and F. J. Timmers, "Safe and convenient procedure for solvent 
purification," Organometallics, vol. 15, no. 5, pp. 1518-1520, 1996.

[52] H. J. Reich and D. J. Cram, "Macro rings. XXXVI. Ring expansion, racemization, and isomer interconversions in the [2.2] paracyclophane system through a diradical intermediate," Journal of the American Chemical Society, vol. 91, no. 13, pp. 3517-3526, 1969.

[53] A. Izuoka, S. Murata, T. Sugawara, and H. Iwamura, "Molecular design and model experiments of ferromagnetic intermolecular interaction in the assembly of high-spin organic molecules. Generation and characterization of the spin states of isomeric bis(phenylmethylenyl)[2.2] paracyclophanes," Journal of the American Chemical Society, vol. 109, no. 9, pp. 2631-2639, 1987.

[54] M. Zhang, H. N. Tsao, W. Pisula, C. Yang, A. K. Mishra, and K. Müllen, "Field-effect transistors based on a benzothiadiazolecyclopentadithiophene copolymer," Journal of the American Chemical Society, vol. 129, no. 12, pp. 3472-3473, 2007.

[55] Z. Dominguez, T.-A. V. Khuong, H. Dang, C. N. Sanrame, J. E. Nuñez, and M. A. Garcia-Garibay, "Molecular compasses and gyroscopes with polar rotors: synthesis and characterization of crystalline forms," Journal of the American Chemical Society, vol. 125, no. 29, pp. 8827-8837, 2003.

[56] N. Miyaura and A. Suzuki, "Palladium-catalyzed crosscoupling reactions of organoboron compounds," Chemical Reviews, vol. 95, no. 7, pp. 2457-2483, 1995.

[57] S. D. Walker, T. E. Barder, J. R. Martinelli, and S. L. Buchwald, "A rationally designed universal catalyst for Suzuki-Miyaura coupling processes," Angewandte Chemie International Edition, vol. 43, no. 14, pp. 1871-1876, 2004.

[58] Th. Förster, "Energiewanderung und fluoreszenz," Naturwissenschaften, vol. 33, no. 6, pp. 166-175, 1946. 

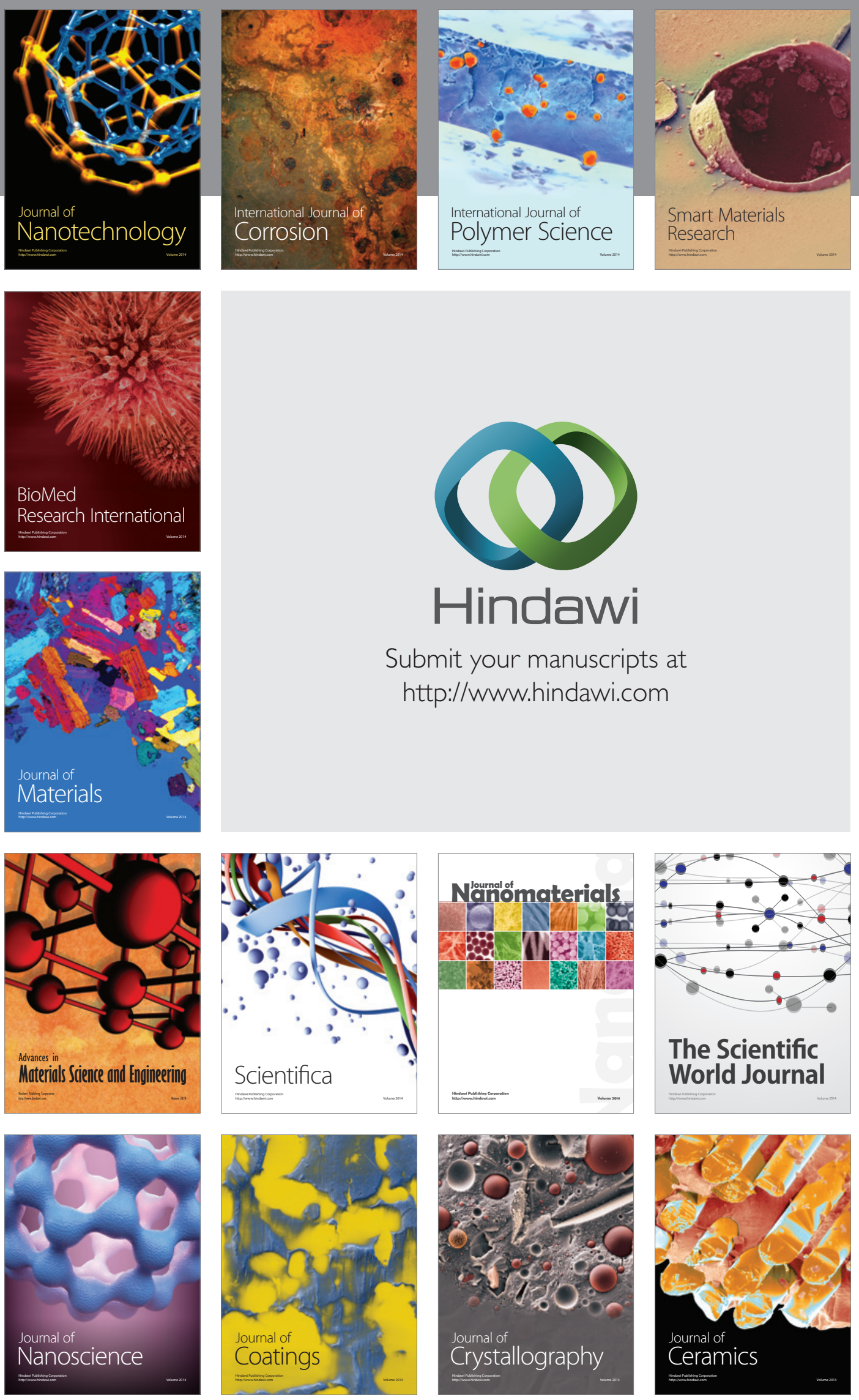

The Scientific World Journal

Submit your manuscripts at

http://www.hindawi.com

\section{World Journal}

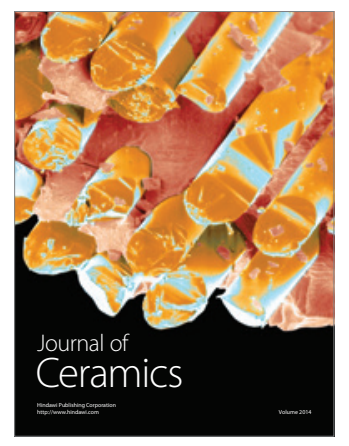

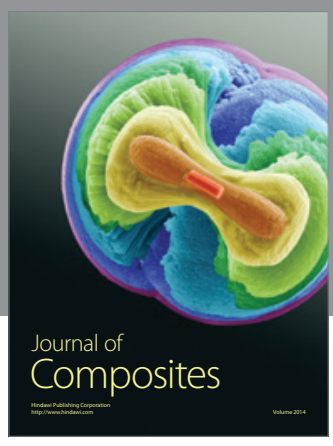
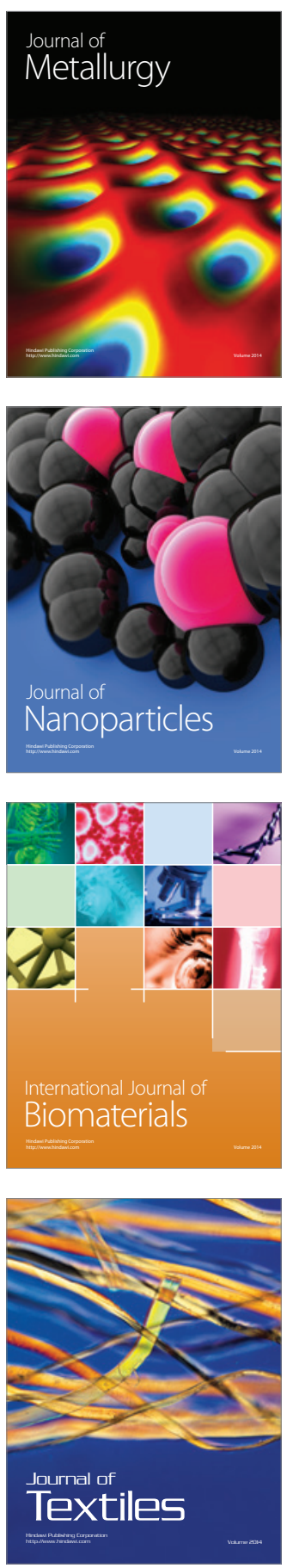